\title{
The Benefits of Indirect Exposure to Trauma: The Relationships among Vicarious Posttraumatic Growth, Social Support, and Resilience in Ambulance Personnel in China
}

\author{
Xiaofei Kang1, Yueyan Fang ${ }^{1}$, Sihan Li ${ }^{1}$, Yadong Liu², Di Zhao ${ }^{1}$, Xiujuan Feng ${ }^{1}$, Yaqi Wang ${ }^{1}$, and Ping Li ${ }^{1 凶}$ \\ ${ }^{1}$ School of Nursing, Shandong University, Shandong, China \\ 2Shandong Chest Hospital, Shandong, China
}

\begin{abstract}
Objective Ambulance personnel who witness trauma experienced by patients have been reported to experience positive changes, known as vicarious posttraumatic growth (VPTG). We examined VPTG and its relationship with social support and resilience among ambulance personnel.

Methods The sample $(\mathrm{n}=227)$ was recruited from six emergency centers in China. The measures included the Posttraumatic Growth Inventory (PTGI), the Social Support Rating Scale (SSRS), and the 10-item Connor-Davidson Resilience Scale (CD-RISC-10). Structure Equation Modeling (SEM) and the bootstrapping procedure were used to examine indirect effects.

Results The participants' mean score for VPTG was $68.96(\mathrm{SD}=15.51)$. Social support had significant direct effects on resilience $(\beta=0.51, p<0.001)$ and VPTG $(\beta=0.25, p=0.001)$, and resilience $(\beta=0.58, p<0.001)$ had a significant direct effect on VPTG. Furthermore, social support had a significant indirect effect $(0.51 \times 0.58=0.30, \mathrm{p}<0.001)$ on VPTG through resilience.

Conclusion Although the nature of the work of ambulance personnel is not expected to change, the negative effects of the trauma they encounter can be reduced by providing them with more support resources and interventions to foster their resilience, which in turn, promote VPTG.

Psychiatry Investig 2018;15(5):452-459
\end{abstract}

Key Words Vicarious posttraumatic growth, Ambulance personnel, Structural Equation Modeling, Resilience, Social support.

\section{INTRODUCTION}

In China, the term "ambulance personnel" (ambulance officers) mainly refers to emergency physicians, nurses, drivers, and stretcher-bearers who provide emergency medical services and hospital transport for patients. As a key component of pre-hospital emergency care, ambulance personnel frequently have to take rapid action in life-and-death circumstances and provide timely medical care in unfamiliar and inconvenient conditions. ${ }^{1}$ Under such stressful conditions, they are exposed to some direct traumatic events, such as being attacked by violent patients or being infected by a severe dis-

Received: March 8, 2017 Revised: August 17, 2017

Accepted: November 8, 2017

$\triangle$ Correspondence: Ping Li, PhD

School of Nursing, Shandong University, 44 Wenhua West Road Jinan, Shangdong 250012, China

Tel: +86-531-88382002, Fax: +86-531-88380226, E-mail: pingli12@sdu.edu.cn (a) This is an Open Access article distributed under the terms of the Creative Commons Attribution Non-Commercial License (http://creativecommons.org/licenses/bync/4.0) which permits unrestricted non-commercial use, distribution, and reproduction in any medium, provided the original work is properly cited. ease. ${ }^{2}$ Moreover, it is an inevitable part of the job of ambulance personnel to be exposed to indirect/vicarious traumatic events, which refers to close contact with direct trauma victims, including witnessing their patients' struggles with illnesses or death, or caring for suffering patients in the process of rescue. ${ }^{3-5}$ As such, ambulance personnel might have a higher risk of developing work-related health problems (e.g., PTSD, depression, fatigue, and job burnout), which reduce their work efficiency and quality of life. . $^{6-10}$

Nevertheless, most ambulance personnel continue to work and live well, for the reason that several factors maybe resist those work-related hazards including positive personal resource (i.e., resilience), healthy organizational environment factors (i.e., high collaboration and integration), and social factors (i.e., sufficient social support). ${ }^{11-13}$ Furthermore, scholars found individuals with aforesaid superior factors even have opportunity to surpass their previous level of functioning as a result of their encounters with adversity. ${ }^{12,14}$ In this context, the term posttraumatic growth (PTG) was introduced, which is defined as "positive psychological changes that an in- 
dividual experience as a result of a struggle with highly challenging life circumstances synonymous with trauma, crisis, or a highly stressful event." ${ }^{35-17}$ PTG has been known as a positive psychological benefit, which involved a process to rebuild one's cognitive schemes, and then provide individual an opportunity to have a new life perspective. . $^{16,18}$

However, PTG has been observed not only in individuals directly exposed to trauma but also in professionals indirectly exposed to traumatic events at work. The phenomenon of PTG occurring in persons indirectly exposed to trauma is specifically known as vicarious posttraumatic growth (VPTG). ${ }^{19-21}$ By definition, VPTG refers to the growth experienced by individuals as a result of working with persons who have been directly affected by a traumatic event. ${ }^{21,22}$ The available literature indicates that VPTG is similar to PTG and reflects positive changes in self-perception, gains in interpersonal relationships, and a new-found appreciation for themselves, others, or even the entire world. ${ }^{21-23}$ The samples used in previous studies investigating VPTG have primarily consisted of professionals, such as mental health workers, ${ }^{21}$ psychiatric nurses, ${ }^{24}$ and firefighters. ${ }^{25}$ Compared to people who work in these services, ambulance personnel have to respond to more emergency calls and have shorter recovery time between emergencies. $^{26,27}$ Although work-related PTG in this area has been reported previously, ${ }^{4,26,28}$ the level of VPTG and its relationship with other predictors warrants further discussion in our cultural context. Such positive attention might contribute to a more comprehensive understanding of the nature of emergency services, which might make ambulance personnel treat their work with more positive schemas, thereby enhancing their job satisfaction and well-being. ${ }^{22}$

According to Tedeschi and Calhoun's theory, social support, as a positive external resource could facilitate PTG. Individuals with high levels of support have more opportunities to narrate their trauma and survival, and to adopt a perspective that can be integrated into a schema change. ${ }^{15,29} \mathrm{~A}$ growing body of literature supports research findings of a positive effect of social support on PTG. ${ }^{30-33}$ One investigation of cancer survivors indicated that social support helped traumatized people reinterpret their present situation, stimulate their cognitive processes, and, in turn, foster their meaning-making process..$^{33}$ In another study on the parents of children undergoing a surgical procedure for a congenital disease, the participants who perceived greater social support were more likely to experience fewer posttraumatic stress symptoms and more positive changes. ${ }^{32}$ However, whether the positive relationship between social support and PTG in persons who have experienced trauma directly, applies to those who have experienced it indirectly, should be investigated further.

Resilience, as a positive internal resource, is regarded as the ability to cope with, adapt to, or bounce back from threatening or challenging situations. ${ }^{34,35}$ Tedeschi and Calhoun have suggested that resilience-related coping strategies can promote PTG. ${ }^{15,29}$ High-resilient individuals typically engage in positive cognitive appraisal and use effective coping responses; thus, they have a greater ability to cope with trauma and even grow from it. ${ }^{36-38}$ Nevertheless, some researchers have put forth the opposite opinion. ${ }^{34}$ They argue that if the trauma experienced by a high-resilient individual is not sufficiently severe to initiate the person's meaning-making process, the individual will have fewer opportunities to develop PTG. ${ }^{15,34}$ Given these conflicting views, further investigations to clarify this relationship are essential and the role of resilience in VPTG among ambulance personnel deserves to be examined.

Social support might also influence resilience ${ }^{39,40}$ by enhancing its role in the recovery from stressful events. ${ }^{41-43} \mathrm{Ni}$ et al. ${ }^{40}$ concluded that individuals with adequate resources for support are more likely to engage in collective activities and maintain friendships with others, thereby, manifesting greater resilience. Based on research findings of the positive relationship between social support and resilience, social support has been hypothesized to influence psychological outcomes via fostering resilience. ${ }^{41,44}$ An investigation of firefighters showed that resilience could mediate the relationship between emotional social support and occupational health. ${ }^{41}$ Given the empirical evidence supporting the mediating effect of resilience on the relationship between social support and psychological outcomes, we deduced VPTG, as a psychological outcome, could be predicted by social support, directly or indirectly through resilience.

We hypothesized that: 1) ambulance personnel experience VPTG; 2) social support, resilience, and VPTG are positively correlated; and 3) the association between social support and VPTG is mediated by resilience.

\section{METHODS}

\section{Participants and procedures}

A total of 238 participants were recruited using a convenience sampling method from six emergency centers in Jinan, China; all the participants had worked as ambulance personnel for at least 3 months. Eleven participants were excluded because of their incomplete responses to the survey. Data from 227 participants were analyzed.

Approval to conduct the study was obtained from the Ethics Committee of the Nursing School of Shandong University (2016-006R), and the written informed consent of all participants was obtained prior to the survey. 


\section{Demographic information}

A questionnaire was developed to collect demographic information, including gender, age, marital status, educational level, monthly household income, length of time employed, and position.

\section{Measurement of vicarious posttraumatic growth}

The Posttraumatic Growth Inventory (PTGI), developed by Tedeschi and Calhoun, ${ }^{29}$ is a 21 -item self-report scale measuring respondents' positive changes after they have struggled with adversity. It is categorized into five major domains: greater appreciation of life, more intimate relationships with others, greater personal strength, recognition of new possibilities in life, and spiritual or religious growth. ${ }^{29}$ We used the Chinese version of PTGI which was developed by translation and backtranslation. Both the global scale (Cronbach's $\alpha=0.90$ ) and subscales (Cronbach's $\alpha=0.67-0.85$ ) of this version have good internal reliability, ${ }^{45}$ which have been widely used among Chinese samples. ${ }^{31,42-44}$ According to published literature, we supposed ambulance personnel had been exposed to work-related trauma. ${ }^{4,5,26,46}$ Thus, the participants were asked to rate the extent to which they perceived experiencing positive changes after witnessing the traumatic experiences of patients' during rescues. The response options for the items ranged from 0 ("I never experienced a positive change as a result of exposure to a traumatic event") to 5 ("I have experienced positive changes to a great degree as a result of exposure to a traumatic event"). The Cronbach's a coefficient for the whole scale in this study was 0.935 , and for the subscales, 0.589 to 0.879 .

\section{Measurement of social support}

The Chinese version of the Social Support Rating Scale (SSRS), developed by Xiao, ${ }^{47}$ is a self-report scale consisting of 10 items that measure three domains of social support: objective support, which refers to actual support received from social networks; subjective support, which refers to perceived support including emotional support; and support-seeking behavior, which refers to behavior in which an individual actively seeks support. The total possible score ranges from 12 to 66 points, with higher scores indicating stronger social support. The internal consistency coefficient of the total scale and subscales among Chinese samples ranged from 0.61 to 0.91 , and the content and construct validities were both satisfactory. ${ }^{40,48,49}$ In present study, the Cronbach's a values for the whole scale and subscales were as follows: overall scale (10 items, $\alpha=0.777$ ), objective support subscale ( 3 items, $\alpha=$ 0.673 ), subjective support subscale ( 4 items, $\alpha=0.669$ ), and support-seeking subscale ( 3 items, $\alpha=0.506$ ).

\section{Measurement of resilience}

The 10-item Connor-Davidson Resilience Scale (CD-RISC-10), developed by Campbell-Sills and Stein, ${ }^{50}$ was extracted from the original 25-item CD-RISC. ${ }^{51}$ The scale reflected the individual's ability to tolerate those experiences which included change, illness, pressure, failure, and pain. Questions are answered using a 5-point scale ranging from 0 ("not true at all") to 4 ("almost always true"). The total scores calculated indicate the ability of an individual to bounce back from various life challenges. The Chinese version has showed excellent psychometric properties, which was widely used in Chinese samples (Cronbach's $\alpha=0.82-0.91) .{ }^{52-55}$ The Cronbach's alpha in present study was 0.921 .

\section{Data analysis}

The data were analyzed in two stages. First, descriptive statistics, independent-sample t-tests, analyses of variance (ANOVA), and Pearson's bivariate correlations were performed using the Statistical Package for Social Sciences, Version 22.0 software (IBM Corp., Armonk, NY, USA). Second, Structural Equation Modeling (SEM) was performed using AMOS 22.0 (IBM Corp.) to analyze the mediating effect of resilience on the relationship between social support and VPTG. In this model, VPTG was a latent variable manifested by relating to others, new possibilities, personal strength, spiritual change, and appreciation of life, with their respective measurement errors (e4-e8). Social support, as a latent variable, was manifested by objective support, subjective support, and supportseeking behaviors, with their respective measurement errors (e3-e1). As resilience was measured using a unidimensional scale, it was an observed variable with the error term (e9) in the model. The hypothesis for the structural path was that social support would have direct and indirect effects on VPTG through resilience, with an unexplained disturbance (e10). Furthermore, indirect effects were assessed using the bootstrapping procedure in AMOS. Based on the procedure set down by MacKinnon et al., ${ }^{56}$ the number of samples generated from the original data by random sampling was 10,000 . The procedure would create $95 \%$ confidence intervals (CI), with a significant indirect effect recognized if zero was not contained within the lower and upper CIs.

\section{RESULTS}

The participants consisted of 103 nurses, 71 physicians, and 53 other ambulance workers (drivers and stretcher-bearers), ranging in age from 22 to 55 years old $(\mathrm{M}=31.76, \mathrm{SD}=6.52)$. Among them, 51.5\% were female; 192 (84.6\%) had junior-college degrees; 155 (68.3\%) were married; 101 (44.5\%) had a monthly income higher than $¥ 3,000$; and approximately half 
(43.6\%) were employed as ambulance personnel longer than 5 years. The independent-sample t tests and ANOVA showed no significant differences in participants' VPTG scores based on their socio-demographic characteristics. These data are shown in Table1.

Table 2 presents the participants' scores on the study's mea- sures and the bivariate correlations among VPTG, social support, and resilience. The mean VPTG score of the ambulance personnel was $68.96(\mathrm{SD}=15.51)$. The mean scores on the five domains of VPTG from highest to lowest were relating to others, new possibilities, personal strength, appreciation of life, and spiritual change. The bivariate correlations showed that

Table 1. Univariate associations of socio-demographic variables with VPTG (N=227)

\begin{tabular}{|c|c|c|c|c|}
\hline Variables & $\mathrm{N}(\%)$ & PTGI Scores $(\mathrm{M} \pm \mathrm{SD})$ & $\mathrm{t} / \mathrm{F}$ & $\mathrm{p}$ \\
\hline Gender & & & -0.238 & 0.812 \\
\hline Female & $117(51.5)$ & $68.72 \pm 15.24$ & & \\
\hline Male & $110(48.5)$ & $69.21 \pm 15.85$ & & \\
\hline Age & & & 0.092 & 0.927 \\
\hline$\leq 30$ years old & $128(56.4)$ & $69.04 \pm 14.47$ & & \\
\hline$>30$ years old & $99(46.6)$ & $68.85 \pm 16.83$ & & \\
\hline Marital status & & & 1.319 & 0.189 \\
\hline Married & $155(68.3)$ & $68.03 \pm 16.15$ & & \\
\hline Unmarried & $72(31.7)$ & $70.94 \pm 13.92$ & & \\
\hline Education level & & & -1.623 & 0.106 \\
\hline High school and bellow & $35(15.4)$ & $65.06 \pm 18.97$ & & \\
\hline Junior-college and above & $192(84.6)$ & $69.67 \pm 14.74$ & & \\
\hline Monthly household income & & & -0.090 & 0.929 \\
\hline$<3,000 \mathrm{RMB}$ & $126(55.5)$ & $68.87 \pm 15.81$ & & \\
\hline$\geq 3,000 \mathrm{RMB}$ & $101(44.5)$ & $69.06 \pm 15.20$ & & \\
\hline Working time & & & 1.233 & 0.219 \\
\hline$\leq 5$ years & $128(56.4)$ & $70.07 \pm 14.58$ & & \\
\hline$>5$ years & $99(43.6)$ & $67.52 \pm 16.59$ & & \\
\hline Position & & & 0.182 & 0.834 \\
\hline Physicians & $71(31.3)$ & $69.80 \pm 14.72$ & & \\
\hline Nurses & $103(45.4)$ & $68.79 \pm 14.75$ & & \\
\hline Others (drivers and stretcher-bearers) & $53(23.3)$ & $68.15 \pm 18.02$ & & \\
\hline
\end{tabular}

VPTG: Vicarious Posttraumatic Growth, PTGI: The Posttraumatic Growth Inventory

Table 2. Means, standard deviations, and correlations between the study variables

\begin{tabular}{|c|c|c|c|c|c|c|c|c|c|c|c|c|}
\hline Variables & Mean \pm SD & 1 & 2 & 3 & 4 & 5 & 6 & 7 & 8 & 9 & 10 & 11 \\
\hline 1. VPTG & $68.96 \pm 15.51$ & 1 & & & & & & & & & & \\
\hline 2. Relating to others & $22.59 \pm 5.68$ & $0.924^{* *}$ & 1 & & & & & & & & & \\
\hline 3. New possibilities & $15.68 \pm 4.40$ & $0.920^{* *}$ & $0.798^{* *}$ & 1 & & & & & & & & \\
\hline 4. Personal strength & $13.98 \pm 3.11$ & $0.871^{* *}$ & $0.726^{* *}$ & $0.734^{* *}$ & 1 & & & & & & & \\
\hline 5. Spiritual change & $6.66 \pm 1.88$ & $0.851^{* *}$ & $0.747^{* *}$ & $0.752^{* *}$ & $0.728^{* *}$ & 1 & & & & & & \\
\hline 6. Appreciation of life & $10.05 \pm 2.43$ & $0.785^{* *}$ & $0.608^{* *}$ & $0.679^{* *}$ & $0.691^{* *}$ & $0.618^{* *}$ & 1 & & & & & \\
\hline 7. Social support & $39.74 \pm 7.81$ & $0.429^{* *}$ & $0.425^{* *}$ & $0.399^{* *}$ & $0.310^{* *}$ & $0.349^{* *}$ & $0.356^{* *}$ & 1 & & & & \\
\hline 8. Objective support & $8.40 \pm 2.92$ & $0.397^{* *}$ & $0.404^{* *}$ & $0.356^{* *}$ & $0.279^{* *}$ & $0.323^{* *}$ & $0.339^{* *}$ & $0.737^{* *}$ & 1 & & & \\
\hline 9. Subjective support & $23.07 \pm 4.82$ & $0.311^{* *}$ & $0.300^{* *}$ & $0.287^{* *}$ & $0.226^{* *}$ & $0.266^{* *}$ & $0.270^{* *}$ & $0.896^{* *}$ & $0.436^{* *}$ & 1 & & \\
\hline 10. Support-seeking & $8.27 \pm 1.99$ & $0.349^{* *}$ & $0.350^{* *}$ & $0.349^{* *}$ & $0.253^{* *}$ & $0.253^{* *}$ & $0.248^{* *}$ & $0.673^{* *}$ & $0.369^{* *}$ & $0.454^{* *}$ & 1 & \\
\hline 11. Resilience & $28.97 \pm 6.75$ & $0.670^{* *}$ & $0.570^{* *}$ & $0.597^{* *}$ & $0.632^{* *}$ & $0.632^{* *}$ & $0.534^{* *}$ & $0.418^{* *}$ & $0.371^{* *}$ & $0.337^{* *}$ & $0.283^{* *}$ & 1 \\
\hline
\end{tabular}

${ }^{* *} \mathrm{p}<0.01$. SD: standard deviation, VPTG: Vicarious Posttraumatic Growth 


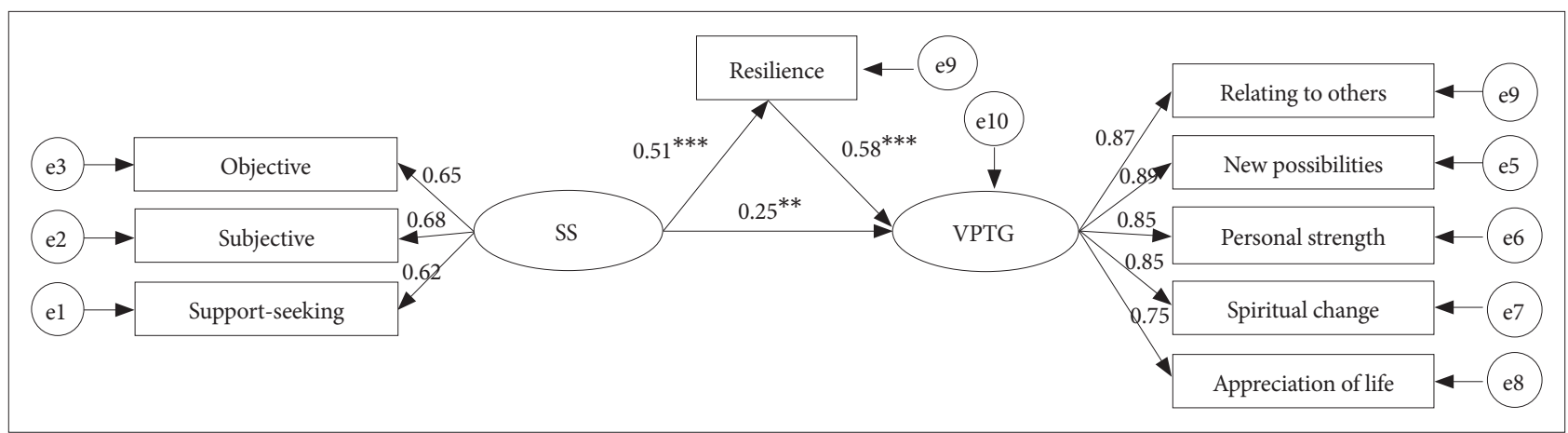

Figure 1. Structural equation modeling of resilience mediated the relationship between social support and VPTG. ${ }^{* *} p<0.01,{ }^{* * *} p<0.001$. SS: social support, VPTG: vicarious posttraumatic growth, e1-e10: the respective measurement errors.

subjective support, objective support, and support-seeking behaviors were positively related to VPTG $(0.311-0.429, \mathrm{p}<0.01)$ and resilience $(0.283-0.418, \mathrm{p}<0.01)$. Resilience was also positively associated with VPTG $(\mathrm{r}=0.670, \mathrm{p}<0.01)$.

The mediation model of resilience and the standardized coefficients for each variable are shown in Figure 1. According to published guidelines to determine model fit, ${ }^{57}$ the criteria used to judge the model's acceptability included: $2 \leq$ a relative chi-square $\left(\chi^{2} / \mathrm{df}\right) \leq 5$; a root mean square error of approximation (RMSEA) $\leq 0.08$; a goodness-of-fit statistic (GFI) $\geq 0.90$; an adjusted goodness-of-fit index (AGFI) $\geq 0.90$; a comparative fit index (CFI) $\geq 0.90$; a Tucker-Lewis Index (TLI) $\geq 0.95$; and a parsimonious normed fit index (PNFI) $\geq 0.50$. All of these indices in our study were within the range of acceptability: $\chi^{2} / \mathrm{df}=2.15, \mathrm{p}=0.001, \mathrm{RMSEA}=0.071, \mathrm{GFI}=0.95$, AGFI=0.91, $\mathrm{CFI}=0.98$, TLI $=0.96$, and $\mathrm{PNFI}=0.66$.

The results of the structural equation modeling (SEM) showed that social support had a significant direct effect on resilience $(\beta=0.51, \mathrm{p}<0.001)$ and VPTG $(\beta=0.25, \mathrm{p}=0.001)$, and resilience $(\beta=0.58, p<0.001)$ had a significant direct effect on VPTG. Furthermore, social support had a total effect of 0.55 on VPTG and an effect of 0.30 that was produced by resilience as the mediating variable. Therefore, resilience was a significant mediator $(0.51 \times 0.58=0.30, \mathrm{p}<0.001)$ of the relationship between social support and VPTG

The results of bootstrapping indicated that the indirect association between social support and VPTG through resilience was significant (95\% CI: $0.218-0.397, \mathrm{p}<0.001)$, which supported our hypothesis that resilience mediates the relationship between social support and VPTG.

\section{DISCUSSION}

This finding is similar to that of previous studies showing that emergency service workers, like firefighters and paramedics who have inevitably been exposed to trauma during rescue, experience work-related PTG. ${ }^{58}$ The VPTG score of the ambulance personnel was $68.96(\mathrm{SD}=15.51)$, which was close to the median of this scale (median: $3 \times 21=63$ ), thus indicating a moderate degree of VPTG. Furthermore, the level of VPTG was higher than ambulance officers in Australia, 3,26,28 which might be due to socio-cultural influences. For instance, China's collectivist culture might make emergency professionals act with more responsibility and pride during an emergency, which to some extent reduces distress and promotes the process of growth. ${ }^{59,60}$ Further, China's traditional cultural value systems (i.e., Confucianism, Taoism) might affect thinking patterns of individuals who might form a more meaningful narrative about trauma. ${ }^{60,61}$ In addition, the score was slightly higher than that reported in studies of psychiatric nurses and social workers. ${ }^{24,30,62}$ Emergency rescues involve extremely urgent life-and-death situations, short recovery times between emergencies, and frequent exposure to trauma experienced by patients. ${ }^{27}$ Such traumatic or stressful circumstances might be powerful enough to challenge the "assumptive world" of ambulance personnel and lead to deliberate rumination, which has been reported to be strongly correlated with VPTG. ${ }^{15,16,30,34}$

Consistent with our hypothesis, social support and resilience were positive predictors of VPTG, with social support having a direct effect on VPTG. One reasonable explanation for this finding is that social support provided the necessary resources for victims to cope with trauma and their negative psychological reactions. ${ }^{63}$ A study of ambulance personnel found that their emotional demands were substantially high. ${ }^{64}$ Therefore, we hypothesized that ambulance personnel with high levels of social support would have closer interpersonal relationships ${ }^{39}$ to meet their emotional demands, which in turn, would protect the ambulance personnel against negative outcomes and promote VPTG.

Resilience emerged as another predictor of VPTG. Similar to persons who have experienced trauma directly, ${ }^{36,65-67}$ the ambulance personnel with high levels of resilience were more likely to regard indirect trauma as a challenge; so, they used problem-focused strategies and were adept at finding some- 
thing positive about their traumatic experiences. These people usually were equipped with some rich mental resources, such as life satisfaction, optimism, and tranquility ${ }^{66}$; therefore, they were more likely to cope with stressful events effectively and even manifest psychological growth.

Based on SEM, resilience mediated the relationship between social support and VPTG among ambulance personnel. Ambulance personnel with greater social support preferred to seek support from others or they believed that others would help them when they encountered negative events. This tendency most likely increased their perceived ability to cope with stress, thereby contributing to greater resilience. Problem-focused coping accompanied by resilience helped them overcome negative events and discover positive aspects of their experiences. ${ }^{39,67}$ These results demonstrated that high levels of social support enhanced resilience, which in turn, facilitated VPTG among the ambulance personnel.

The limitations of this study should be mentioned. First, it is difficult to infer causality from the cross-sectional design. Although the SEM indicated some directions of effect, which supports the assumption that social support could influence resilience, the relationship between the two variables might be bidirectional. Therefore, the order and directionality of causality's relationship with social support and resilience need further verification through longitudinal studies. Second, the selfreport measures used might weaken the potential strength of the conclusions. Besides, no instrument has been developed to specifically measure VPTG. ${ }^{68}$ It is measured using the PTGI, which might lead to a slight reporting bias. Henceforth, VPTG should be measured using qualitative methods and more accurate instruments. Third, VPTG was measured based on work-related indirect trauma exposure, in which variation from other personal trauma might exist simultaneously. Fourth, a convenience sampling method is highly vulnerable to selection bias. The results of the study should be treated keeping these limitations in mind.

Despite these limitations, there are significant implications for clinical practice. Exploring posttraumatic positive changes following work-related traumatic events and the mediating role of resilience might pave the way for new views about adding the concept of VPTG in inductive education or postevent conclusion, and attending to the signs of VPTG and its influencing factors in psychological interventions. Although the nature of the work of ambulance personnel is not expected to change, increasing such positive focus might help make ambulance personnel realize that they can grow from experiencing work-related trauma, thus boosting enthusiasm and effectiveness in emergency services, which might play a role in preventing exhaustion and employee turnover. ${ }^{69,70}$ Meanwhile, the important mediating role of resilience in the rela- tionship between social support and VPTG should also be highlighted. Henceforth, we should pay attention to not only the establishment of social support systems but also the implementation of resilience-building interventions like mindfulness meditation-based exercises. ${ }^{71}$

\section{Acknowledgments}

The study was supported by grants from Shandong Province Natural Science Foundation (ZR2015HM064) and the Innovation Foundation for Young Talent Team of Shandong University (IFYT15010). We sincerely thank the generous contributions of the research participants and the staff who assisted with data collection during the study.

\section{REFERENCES}

1. Sterud T, Hem E, Ekeberg O, Lau B. Occupational stressors and its organizational and individual correlates: a nationwide study of Norwegian ambulance personnel. BMC Emerg Med 2008;8:16.

2. Alma J. Perceptions of stress in British ambulance personnel. Work Stress 1988;2:319-326.

3. Kirby R, Shakespeare-Finch J, Palk G. Adaptive and maladaptive coping strategies predict posttrauma outcomes in ambulance personnel. Traumatology 2011;17:25-34.

4. Ogińskabulik N, Kobylarczyk M. Relation between resiliency and post-traumatic growth in a group of paramedics: the mediating role of coping strategies. Int J Occup Med Environ Health 2015;28:707-719.

5. Bellagamba G, Gionta G, Senergue J, Bèque C, Lehuchermichel MP. Organizational factors impacting job strain and mental quality of life in emergency and critical care units. Int J Occup Med Environ Health 2015;28:357-367.

6. Sterud T, Ekeberg $\varnothing$, Hem E. Health status in the ambulance services: a systematic review. BMC Health Serv Res 2006;6:82.

7. Pek E, Fuge K, Marton J, Banfai B, Gombos GC, Betlehem J. Cross-sectional survey on self-reported health of ambulance personnel. Scand J Trauma Resusc Emerg Med 2015;23:14.

8. Alexander DA, Klein S. Ambulance personnel and critical incidents: impact of accident and emergency work on mental health and emotional well-being. Br J Psychiatry 2001;178:76-81.

9. Fani K, Bebetsos E. The relationship between burnout, PTSD symptoms and injuries among ambulance personnel. Sport Sci 2016;9:7-13.

10. Clohessy S, Ehlers A. PTSD symptoms, response to intrusive memories and coping in ambulance service workers. Br J Clin Psychol 1999;38: 251-265.

11. Sili A, Fida R, Vellone E, Gianlorenzi A, Alvaro R. Organizational health and quality of life: survey among ambulance nurses in prehospital emergency care. Med Lav 2011;102:511-522.

12. Cicognani E, Pietrantoni L, Palestini L, Prati G. Emergency workers' quality of life: the protective role of sense of community, efficacy beliefs and coping strategies. Soc Indic Res 2009;94:449-463.

13. Rusli BN, Edimansyah BA, Naing L. Working conditions, self-perceived stress, anxiety, depression and quality of life: a structural equation modelling approach. BMC Public Health 2008;8:48.

14. Calhoun LG, Tedeschi RG, Cann A, Hanks EA. Positive outcomes following bereavement: paths to posttraumatic growth. Psychol Belg 2010; 50:125-143.

15. Tedeschi RG, Calhoun LG. Posttraumatic growth: conceptual foundations and empirical evidence. Psychol Inquiry 2004;15:1-18.

16. Picoraro JA, Womer JW, Kazak AE, Feudtner C. Posttraumatic growth in parents and pediatric patients. J Palliat Med 2014;17:209-218.

17. Blix I, Hansen MB, Birkeland MS, Nissen A, Heir T. Posttraumatic growth, posttraumatic stress and psychological adjustment in the aftermath of the 2011 Oslo bombing attack. Health Qual Life Outcomes 2013;11:160. 
18. Bauwens J, Tosone C. Professional posttraumatic growth after a shared traumatic experience: Manhattan clinicians' perspectives on post-9/11 practice. J Loss Trauma 2010;15:498-517.

19. Beck CT, Eaton CM, Gable RK. Vicarious posttraumatic growth in labor and delivery nurses. J Obstet Gynecol Neonatal Nurs 2016;45:801812 .

20. Cosden M, Sanford A, Koch LM, Lepore CE. Vicarious trauma and vicarious posttraumatic growth among substance abuse treatment providers. Subst Abus 2016;37:619-624.

21. Hyatt-Burkhart D. The experience of vicarious posttraumatic growth in mental health workers. J Loss Trauma 2014;19:452-461.

22. Arnold D, Calhoun LG, Tedeschi R, Cann A. Vicarious posttraumatic growth in psychotherapy. J Humanist Psychol 2005;45:239-263.

23. Calhoun LG, RG Tedeschi. Facilitating posttraumatic growth: a clinician's guide. Health Quality Life Outcomes 1999;12:34.

24. Zerach G, Shalev TB. The relations between violence exposure, posttraumatic stress symptoms, secondary traumatization, vicarious post traumatic growth and illness attribution among psychiatric nurses. Arch Psychiatr Nurs 2015;29:135-142.

25. Ogińska-Bulik N, Kobylarczyk M. Association between resiliency and posttraumatic growth in firefighters: the role of stress appraisal. Int J Occup Saf Ergon 2016;22:40-48.

26. Shakespearefinch JE, Smith SG, Gow KM, Embelton G, Baird L. The prevalence of post-traumatic growth in emergency ambulance personnel. Traumatology 2003;9:58-71.

27. Pyper Z, Paterson JL. Fatigue and mental health in Australian rural and regional ambulance personnel. Emerg Med Australas 2015;28:62-66.

28. Shakespearefinch J, Gow K, Smith S. Personality, coping and posttraumatic growth in emergency ambulance personnel. Traumatology 2005; 11:325-334.

29. Tedeschi RG, Calhoun LG. The posttraumatic growth inventory: measuring the positive legacy of trauma. J Trauma Stress 1996;9:455-471.

30. Rhee YS, Ko YB, Han IY. Posttraumatic growth and related factors of child protective service workers. Ann Occup Environ Med 2013;25:6.

31. Ray S. The role of event centrality, coping and social support in resilience and posttraumatic growth among women and men. Int J Ment Health Pr 2015;17:78-96.

32. Li Y, Cao F, Cao D, Wang Q, Cui N. Predictors of posttraumatic growth among parents of children undergoing inpatient corrective surgery for congenital disease. J Pediatr Surg 2012;47:2011-2021.

33. Scrignaro M, Barni S, Magrin ME. The combined contribution of social support and coping strategies in predicting post-traumatic growth: a longitudinal study on cancer patients. Psychooncology 2011;20:823-831.

34. Wu K, Zhang Y, Liu Z, Zhou P, Wei C. Coexistence and different determinants of posttraumatic stress disorder and posttraumatic growth among Chinese survivors after earthquake: role of resilience and rumination. Front Psychol 2015;6:1043.

35. Wu Z, Xu J, Sui Y. Posttraumatic stress disorder and posttraumatic growth coexistence and the risk factors in Wenchuan earthquake survivors. Psychiatry Res 2016;237:49-54.

36. Zoellner T, Maercker A. Posttraumatic growth in clinical psychology- a critical review and introduction of a two component model. Clin Psychol Rev 2006;26:626-653.

37. Bensimon M. Elaboration on the association between trauma, PTSD and posttraumatic growth: the role of trait resilience. Pers Individ Diff 2012;52:782-787.

38. Sexton MB, Byrd MR, Von Kluge S. Measuring resilience in women experiencing infertility using the CD-RISC: examining infertility-related stress, general distress, and coping styles. J Psychiatr Res 2010;44:236241.

39. Mo PK, Lau JT, Yu X, Gu J. The role of social support on resilience, posttraumatic growth, hopelessness, and depression among children of HIVinfected parents in mainland China. AIDS Care 2014;26:1526-1533.

40. Ni C, Chow MC, Jiang X, Li S, Pang SM. Factors associated with resilience of adult survivors five years after the 2008 Sichuan earthquake in
China. PLoS One 2015;10(3):e0121033.

41. Bernabé M, Botia JM. Resilience as a mediator in emotional social support's relationship with occupational psychology health in firefighters. J Health Psychol 2016;21:1778-1786.

42. Fletcher D, Sarkar M, Wylleman P, Johnson U. A grounded theory of psychological resilience in Olympic champions. Psychol Sport Exerc 2012;13:669-678.

43. Dyrbye LN, Power DV, Massie FS, Eacker A, Harper W, Thomas MR, et al. Factors associated with resilience to and recovery from burnout: a prospective, multi-institutional study of US medical students. Med Educ 2010;44:1016-1026.

44. Li J, Theng YL, Foo S. Does psychological resilience mediate the impact of social support on geriatric depression? An exploratory study among Chinese older adults in Singapore. Asian J Psychiatr 2015;14:22-27.

45. Ho SM, Chan CL, Ho RT. Posttraumatic growth in chinese cancer survivors. Psychooncology 2004;13:377-389.

46. Jurišová E. Coping strategies and post-traumatic growth in paramedics: moderating effect of specific self-efficacy and positive/negative affectivity. Studia Psychologica 2016;58:259-275.

47. Xiao S. Theoretical basis and application in research of social support rating scale. J Clin Psychiatry 1994;4:98-100.

48. Liu JW, LI F, Lian YL. Investigation of reliability and validity of the social support scale. In Chinese. J Xinjiang Med Univ 2008;31:1-3.

49. Shi L, Wang L, Jia X, Li Z, Mu H, Liu X, et al. Prevalence and correlates of symptoms of post-traumatic stress disorder among Chinese healthcare workers exposed to physical violence: a cross-sectional study. BMJ Open 2017;7:e016810.

50. Campbellsills L, Stein MB. Psychometric analysis and refinement of the Connor-davidson Resilience Scale (CD-RISC): validation of a 10-item measure of resilience. J Trauma Stress 2007;20:1019-1028.

51. Connor KM, Davidson JR. Development of a new resilience scale: the Connor-Davidson Resilience Scale (CD-RISC). Depress Anxiety 2003; 18:76-82.

52. Wang L, Shi Z, Zhang Y, Zhang Z. Psychometric properties of the 10item Connor-Davidson Resilience Scale in Chinese earthquake victims. Psychiatry Clin Neurosci 2010;64:499-504.

53. Duan W, Guo P, Gan P. Relationships among trait resilience, virtues, post-traumatic stress disorder, and post-traumatic growth. PLoS One 2015; 10:e0125707.

54. Ye ZJ, Qiu HZ, Li PF, Chen P, Liang MZ, Liu ML, et al. Validation and application of the Chinese version of the 10-item Connor-Davidson Resilience Scale (CD-RISC-10) among parents of children with cancer diagnosis. Eur J Oncol Nurs 2017;27:36-44.

55. Liu X, Liu C, Tian X, Zou G, Li G, Kong L, et al Associations of perceived stress, resilience and social support with sleep disturbance among community-dwelling adults. Stress Health 2016;32:578-586.

56. Mackinnon DP, Lockwood CM, Williams J. Confidence limits for the indirect effect: distribution of the product and resampling methods. Multivariate Behav Res 2004;39:99.

57. Hooper D, Coughlan J, Mullen MR. Structural equation modeling: guidelines for determining model fit. EJBRM 2008;6:53-60.

58. Leykin D, Lahad M, Bonneh N. Posttraumatic symptoms and posttraumatic growth of Israeli firefighters, at one month following the Carmel fire disaster. Psychiatry J 2013;2013:274121.

59. Kehl D, D Knuth, L Hulse, S Schmidt; BeSeCu-Group. Predictors of postevent distress and growth among firefighters after work-related emergencies--A cross-national study. Psychol Trauma 2015;7:203-211.

60. Tzipi Weiss, Roni Berger. Posttraumatic Growth and Culturally Competent Practice. In: Ho SMY, Y Bai, Editors. Posttraumatic Growth in Chinese Culture. Canada: John Wiley \& Sons Inc, 2010, p.147-156.

61. Xu X, Hu ML, Song Y, Lu ZX, Chen YQ, Wu DX, et al. Effect of positive psychological intervention on posttraumatic growth among primary healthcare workers in China: s preliminary prospective study. Sci Rep 2016;6:39189.

62. Gibbons S, Murphy D, Joseph S. Countertransference and positive 
growth in social workers. J Soc Work Pract 2011;25:17-30.

63. Zhou X, Wu X, Li X, Zhen R. The role of posttraumatic fear and social support in the relationship between trauma severity and posttraumatic growth among adolescent survivors of the Yaan earthquake. Int J Psychol 2018;53:150-156.

64. Hansen CD, Rasmussen K, Kyed M, Nielsen KJ, Andersen JH. Physical and psychosocial work environment factors and their association with health outcomes in Danish ambulance personnel - a cross-sectional study. BMC Public Health 2012;12:534.

65. Yu Y, Peng L, Chen L, Long L, He W, Li M, et al. Resilience and social support promote posttraumatic growth of women with infertility: the mediating role of positive coping. Psychiatry Res 2014;215:401-405.

66. Zhai Y, Liu K, Zhang L, Gao H, Chen Z, Du S, et al. The relationship between post-traumatic symptoms, parenting style, and resilience among adolescents in Liaoning, China: a cross-sectional study. PLoS One 2015; 10:e0141102.

67. Angel CM. Resilience, post-traumatic stress, and posttraumatic growth: Veterans' and active duty military members' coping trajectories following traumatic event exposure. Nurse Educ Today 2016;47:57-60.

68. Ben-Porat A, Itzhaky H. Implications of treating family violence for the therapist: secondary traumatization, vicarious traumatization, and growth. J Fam Viol 2009;24:507-515.

69. Chopko BA. Posttraumatic distress and growth: an empirical study of police officers. Am J Psychother 2010;64:55-72.

70. Morris BA, Shakespeare-Finch J, Rieck M, Newbery J. Multidimensional nature of posttraumatic growth in an Australian population. J Trauma Stress 2005; 18:575-585.

71. Crowder R, Sears A. Building resilience in social workers: an exploratory study on the impacts of a mindfulness-based intervention. Aust Soc Work 2017;70:17-29. 